\title{
ReVitalisasi PASAR IKAN REJOMUlyo Sebagai DeSTINASI WiSATA Dengan Pendekatan Arsitektur Perilaku Di Kota SEMARANG
}

\author{
Crustasia Aji Westriani, Mohamad Asrori, Made Suastika \\ Program Studi Arsitektur \\ Fakultas Teknik \\ Universitas Sebelas Maret, Surakarta \\ Email : crustasiaajiwestriani@gmail.com
}

\begin{abstract}
The background of revitalization Rejomulyo fish market is the condition of this market was getting worse and desolate from buyers. Increasingly of tourist attraction and a lot of fish lovers community at Semarang city becomes away to resurrect this market including the physical of this building, economics, social, and bargaining culture. Therefore, Environmental Behavior Architecture was chosen to make fish market become recreational, effective, and efficient appropriate with user behavior. The purpose of this design was to make Rejomulyo fish market as a city tourist destination, with the result this market can be used again and supply the needs of society. The problem of the design is how to use both of two buildings in the market with different function in order to have competitive quality. So that created appropriate device with user's behavior. The method used is by combining the principles of the Architecture of Conduct, regulations Indonesian Trade Minister regarding the revitalization of the market, standardize the fish market, and the real condition of the Rejomulyo fish market. The result from this design is fish market design which is hygienic place and there is a place for fish exhibition. Besides that, it also became a place for fish lover's community to make positive activity for community and several of fish lovers. The purpose of Architecture Behavioral was to restore function Rejomulyo fish market, as well as a tourist destination Semarang comfortable, clean, effective, and efficient.
\end{abstract}

Keywords: Environmental Behaviour, Fish Market, Revitalization, Urban Tourism

\section{PENDAHULUAN}

Revitalisasi merupakan kegiatan menghidupkan kembali suatu tempat atau kawasan yang mencakup perbaikan fisik, ekonomi, dan sosial yang pelaksanaannnya membutuhkan keterlibatan masyarakat luas.

Dalam hal ini kegiatan yang dilakukan yaitu revitalisasi pasar. Perkembangan pasarpasar tradisional dewasa ini terlihat semakin berat karena semakin pesatnya berkembang sejumlah pasar modern (mini market) yang sudah mulai berkembang sampai ke pelosokpelosok desa. Budaya pada pasar yang menjadi ciri khas pasar tradisional juga mulai menghilang. Oleh karena itu, kegiatan ini dilakukan karena perlunya kegiatan tersebut dalam menghidupkan kembali secara fisik dan non fisik bangunan agar dapat berfungsi sesuai fungsinya.

Pasar Ikan Rejomulyo merupakan salah satu pasar tradisional di Kota Semarang yang menjual berbagai jenis ikan. Pasar ini memiliki dua bangunan dengan fungsi yang berbeda. Bangunan pasar dengan kondisi yang semakin buruk dan sepi pembeli. Hal inilah yang perlu perhatian untuk melakukan revitalisasi pasar.

Kota Semarang merupakan salah satu kota besar, banyak komunitas atau perkumpulan yang ada pada kota tersebut. Kota Semarang memiliki beberapa komunitas yang berhubungan dengan ikan hias. Namun di sisi lain, mereka tidak dapat membuat suatu acara yang menunjukkan keberadaan komunitas tersebut. Hal ini dikarenakan kebutuhan ruang sebagai media penyalur komunitas tidak ada dan tidak semua ruangruang yang ada dapat mendukung beberapa komunitas.

Oleh karena itu, dengan adanya Revitalisasi Pasar Ikan Rejomulyo sebagai Destinasi Wisata ini dapat menampung kegiatan beberapa komunitas ikan yang ada di 
Kota Semarang. Dengan begitu, pasar yang tadinya sepi pengunjung dapat menjadi ramai dengan adanya kegiatan penunjang dari beberapa komunitas ikan Kota Semarang.

Kota Semarang merupakan salah satu kota dengan daya tarik wisatawan yang semakin meningkat setiap tahunnya (www.bappeda.semarangkota.go.id, 2014). Hal ini didukung dengan banyaknya destinasi wisata kota yang menggugah minat para wisatawan. Dengan potensi yang ada, Pasar Ikan Rejomulyo dapat dijadikan sebagai destinasi atau tujuan wisata para wisatawan Kota Semarang. Pasar ini dapat menjadi tujuan wisatawan untuk memperoleh salah satu buah tangan khas dari Kota Semarang.

Pasar ikan merupakan suatu pasar tradisional yang menjual barang sesuai jenis barang konsumsinya. Banyak kegiatan yang terjadi pada pasar ikan dan berbeda dengan jenis pasar tradisional pada umumnya. Sebuah sikap arsitektural tidak lepas oleh desain yang relevan dan mendukung kegiatan yang ada pada objek rancang bangun. Lambat laun akan terbentuk lingkungan binaan yang berkualitas dan sesuai dengan kondisi penggunanya. Pendekatan Arsitektur Perilaku memiliki potensi untuk meningkatkan efektivitas dalam perancangan Pasar Ikan Rejomulyo. Oleh karena itu, peran arsitektur sangat diperlukan dalam membentuk wadah yang sesuai kebutuhan dengan tetap memperhatikan kegiatan pada lingkungan pasar tersebut.

\section{METODE}

Metode yang digunakan pada perancangan Revitalisasi Pasar Ikan Rejomulyo dimulai dari studi lapangan yang digunakan sebagai data kualitatif untuk mengumpulkan data, guna mengetahui kegiatan pengguna pasar. Kemudian menyajikan data yang dapat menunjang objek rancang bangun menjadi destinasi wisata kota. Selain itu, pendekatan Arsitektur Perilaku dilakukan dengan cara melakukan observasi pada objek dan melakukan pengamatan perilaku pengguna pasar ikan. Data baik dari segi fisik dan non fisik yang didapat, kemudian dianalisis dan diterapkan pada Revitalisasi Pasar Ikan Rejomulyo. Dari hasil analisis tersebut, sehingga akan tercapai perencanaan dan perancangan pasar ikan yang optimal dan sesuai dengan kenyaman pengguna.

\section{ANALISIS}

A. Analisis Makro (Kota Semarang)

Pada analisis ini mengenai analisis

Kota Semarang yang mendukung kegiatan pada Pasar Ikan Rejomulyo yang meliputi, analisis aksesibilitas dan analisis infrastruktur.

B. Analisis Mezo (Daerah Rejomulyo)

Analisis mezo merupakan analisis Daerah Rejomulyo yang merupakan daerah tempat tapak objek perancangan dan perencanaan yang menjadi daya dukung pada objek. Pada analisis ini meliputi analisis aksesibilitas dan analisis transportasi publik Daerah Rejomulyo.

C. Analisis Mikro (Pasar Ikan Rejomulyo yang Direncanakan)

1. Analisis Pengguna

Pengguna dalam Pasar Ikan sebagai Destinasi Wisata disesuaikan dengan kegiatan dan perannya masing-masing pada bangunan, meliputi

a. Pengelola

b. Pengunjung

- Pedagang

- Pembeli

- Wisatawan atau Pelancong

2. Analisis Kebutuhan Ruang

Kebutuhan Ruang diperoleh dari beberapa kegiatan yang dilakukan pengguna pasar meliputi,

a. Kelompok Kegiatan Utama

Jenis ruang yang dibutuhkan dalam kelompok kegiatan utama pasar ikan :

- Kios Penjualan

- Tempat Parkir

- Dropping area

- Tempat penyimpanan es

- Foodcourt

- Ruang informasi

b. Kegiatan Penunjang

Jenis ruang yang dibutuhkan dalam kelompok kegiatan penunjang pasar ikan : 
- Ruang Workshop

- Mushola

- Tempat Pameran

- Kamar Mandi

- ATM centre

c. Kegiatan Pengelola

Jenis ruang yang dibutuhkan dalam kelompok kegiatan pengelola pasar ikan :

- Ruang kerja

- Laboratorium uji

- Dropping area

- Ruang Genset

- Ruang Janitor

- Ruang Keamanan

\section{Analisis Lokasi}

Lokasi perencanaan terletak pada lahan kawasan pasar yang lama dengan mengoptimalkan potensi yang ada dan sekaligus dijadikan destinasi wisata sebagai salah satu upaya dalam revitalisasi.

Berikut ini adalah tapak dari Pasar Ikan Rejomulyo (lihat Gambar. 1) dan juga sebagai rencana tapak yang akan digunakan sebagai lahan perencanaan Revitalisasi Pasar Ikan Rejomulyo di Jalan Pengapon,

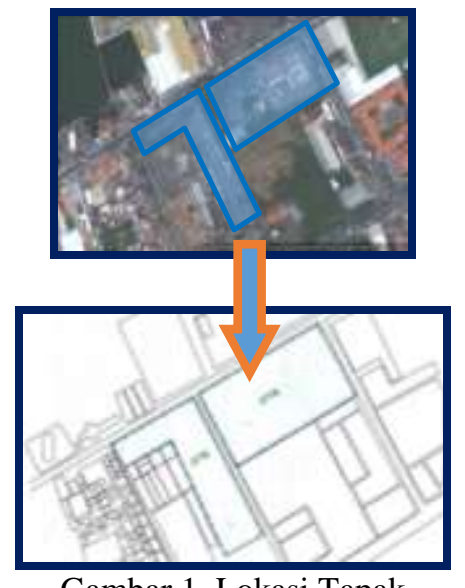

Gambar 1. Lokasi Tapak

Dari tapak yang ada, tapak terdiri dari dua yang dipisahkan oleh jalan lingkungan dengan lebar $\pm 7 \mathrm{~m}$ (lihat Gambar. 1). Tapak yang telah tersedia dan digunakan kembali sebagai tapak Revitalisasi Pasar Ikan Rejomulyo sebagai Destinasi Wisata Kota Semarang, memiliki luasan keseluruhan $\pm 2,5 \mathrm{Ha}$ (lihat Gambar. 2)

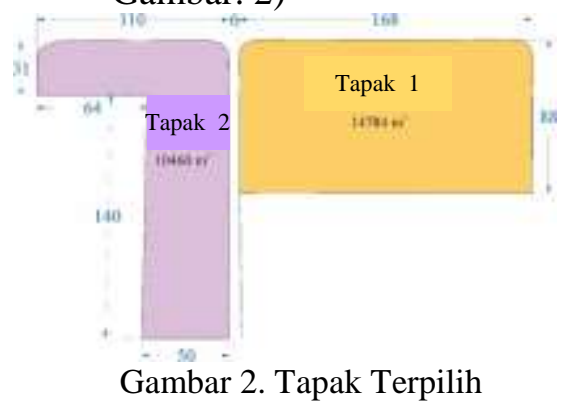

4. Analisis Pencapaian dan Sirkulasi Analisis pencapaian dan sirkulasi pada tapak, berbasiskan pada prinsip Arsitektur Perilaku pada kenyamanan secara fisik. Kenyaman secara fisik dapat ditempuh melalui pencapaian dan sirkulasi yang mudah bagi pengguna menuju bangunan.

a. Analisis Pencapaian

Tujuan : Mendapatkan Main Entrance dan Side Entrance sebagai jalan masuk menuju tapak yang sesuai dengan fungsi bangunan dengan memanfaatkan kondisi lingkungan di sekitarnya.

Dasar Pertimbangan

- Sirkulasi lalu lintas sekitar tapak, keberadaan $M E$ dan $S E$ tidak menyebabkan kemacetan

- Menyesuaikan dengan arah pergerakan lalu lintas di sekitarnya

- Kemudahan pencapaian dari jalan utama

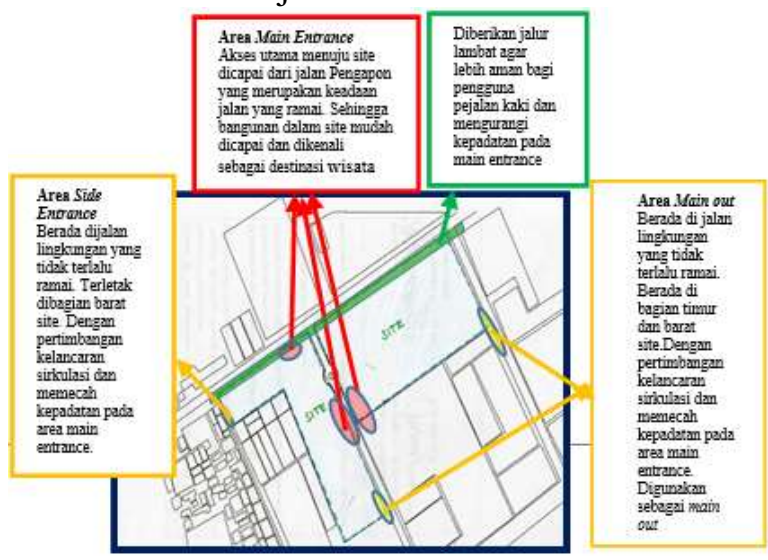

Gambar 3. Analisis Pertimbangan Pencapaian 
Hasil analisis pencapaian pada tapak (lihat Gambar. 3) akan dijadikan sebagai bahan acuan untuk perencanaan selajutnya dalam mendesain Pasar Ikan Rejomulyo yang sesuai dengan perilaku pengguna.

b. Analisis Sirkulasi

Tujuan : Memperhatikan pergerakan manusia dan kendaraan ke dalam atau ke luar tapak. Serta perilaku manusia dalam mencapai kelompok bangunan yang ada.

Dasar Pertimbangan :

- Memberikan kenyaman dan kejelasan sirkulasi baik bagi pengguna

- Memisahkan alur sirkulasi antara pejalan kaki dan kendaraan

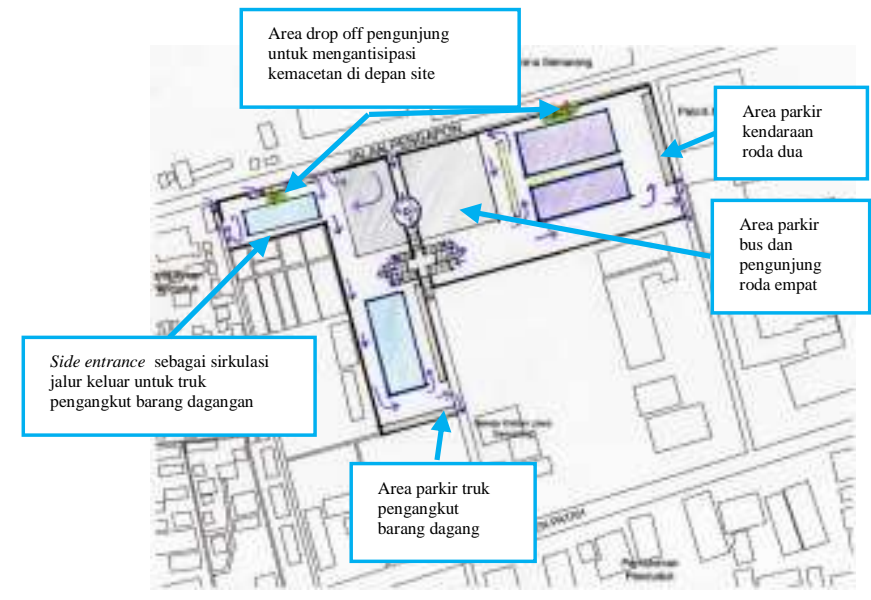

Gambar 4. Analisis Pertimbangan Sirkulasi

Hasil analisis sirkulasi pada tapak (lihat Gambar. 4) terdiri dari dua jenis sirkulasi yaitu sirkulasi untuk pejalan kaki dan sirkulasi untuk pengendara. Sirkulasi pejalan kaki diberikan pedestrian agar tetap memberikan kenyamanan.

5. Analisis Lingkungan

Dalam mendukung pendekatan Arsitektur Perilaku, maka analisis ini diperlukan guna memberikan kenyamanan secara fisik dan faktor fisiologis yang memengaruhi, sehingga akan menghasilkan kenyamanan psikis pada pelaku Pasar Ikan Rejomulyo.

a. Analisis Pergerakan Matahari Tujuan : Mengkondisikan ruang pada bangunan yang mempengaruhi langsung terhadap intensitas sinar matahari yang merupakan faktor fisiologis dalam prinsip Arsitektur Perilaku.

Dasar Pertimbangan :

- Prinsip Arsitektur Perilaku pada faktor fisiologis

- Kondisi lingkungan

b. Analisis Kebisingan

Tujuan : Memecahkan masalah akibat kebisingan untuk mempertimbangkan ruangruang bangunan seperti ruang seminar.

Dasar Pertimbangan :

- Prinsip Arsitektur Perilaku pada kenyaman secara psikis yang memengaruhi kenyamanan fisik pengguna

- Intensitas kebisingan lingkungan

- Penempatan pemintakatan berdasarkan kebutuhan ketenangan

\section{c. Analisis Iklim}

Tujuan : Memecahakan masalah akibat iklim terkait dengan arah angin sebagai pertimbangan desain bangunan yang nyaman dengan perilaku pengguna.

Dasar Pertimbangan

- Prinsip Arsitektur Perilaku pada faktor fisiologis

- Ruang-ruang yang dimungkinkan memiliki kelembaban 


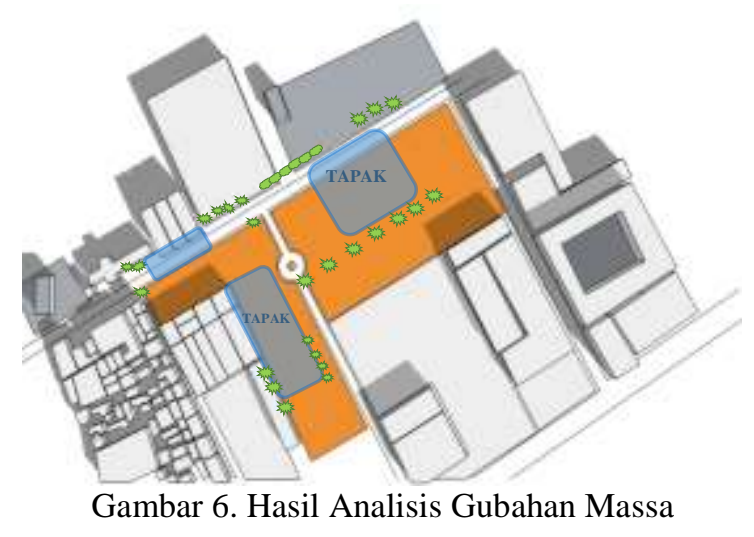

Hasil analisis lingkungan berupa pemberian barier berupa vegetasi di sekitar tapak berfungsi untuk pemecah angin yang masuk ke dalam tapak dan mengurangi kebisingan yang terjadi di luar tapak (lihat Gambar. 5).

6. Analisis Bentuk dan Gubahan Massa

a. Analisis Bentuk

Hal-hal yang menjadi dasar pertimbangan meliputi karakter yang ditampilkan oleh bentuk-bentuk yang akan digunakan, kondisi bentuk tapak, dan nilai estetika bangunan. Kemudian dari bentuk bangunan akan mendapat mendukung kegiatan di dalamnya.

b. Analisis Gubahan Massa Analisis gubahan massa merupakan proses pembentukan massa yang disesuaikan dengan kondisi tapak pasar ikan (lihat Gambar. 6).
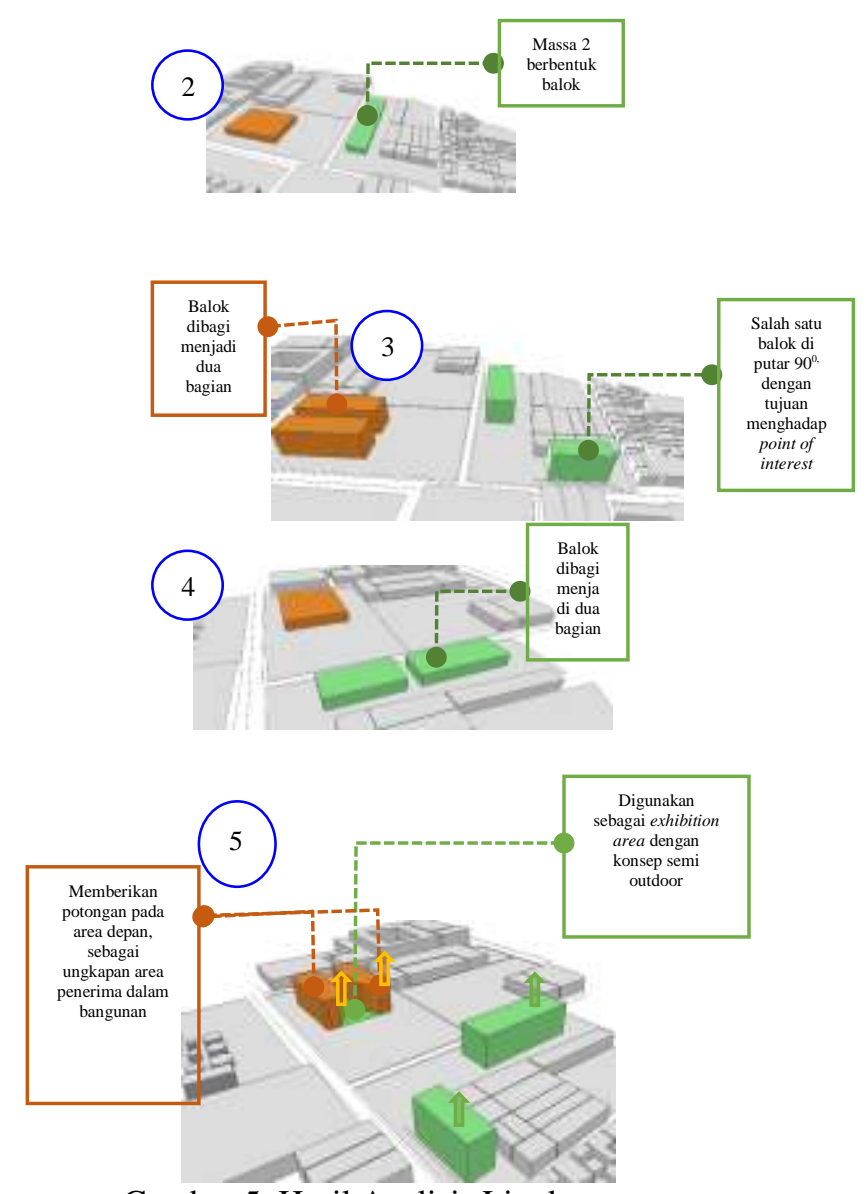

Gambar 5. Hasil Analisis Lingkungan

Dari hasil analisis gubahan massa, akan mendapatkan bentuk bangunan yang sesuai kegiatan dan perilaku pengguna pasar ikan.

7. Analisis Penghubung Bangunan Pasar Ikan Rejomulyo memiliki dua tapak yang berbeda, sebagai penghubung bangunan digunakan teori Simbiosis Intermediate. Pada prinsipnya, teori ini untuk menghubungakan dua bangunan yang berbeda tapak, agar tercipta hubungan yang dinamis yang berupa underpass. 


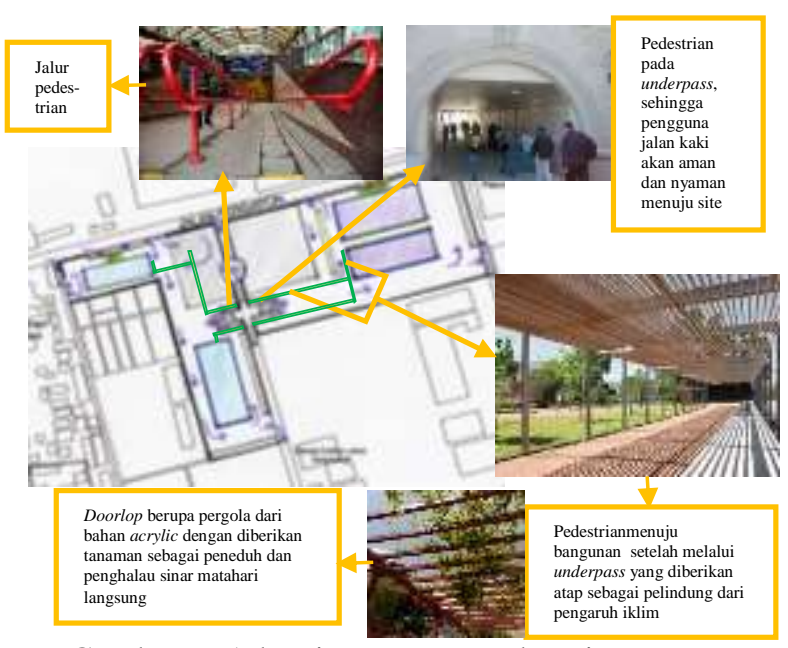

Gambar 9. Adopsi Mercusuar sebagai Menara

Hasil analisis ini menjadikan tapak untuk memiliki pedestrian yang nyaman dan aman dilalui pengunjung pejalan kaki di sekitar tapak (lihat Gambar. 7). Dengan memberikan jalur pedestrian, pejalan kaki dapat dengan nyaman menikmati kondisi sekitar tapak.

8. Analisis Tampilan Bangunan Tampilan bangunan Pasar Ikan Rejomulyo dirancang sedemikian rupa sehingga menimbulkan kesan yang dinamis dengan memperkuat citra fungsi bangunan sebagai destinasi wisata dengan pengguna dan kegiatan yang berbeda.

\section{a. Sculpture}

Sculpture menjadi pilihan sebagai pengikat kedua bangunan dengan tapak yang bersebelahan (lihat Gambar. 8) agar terlihat lebih dinamis.

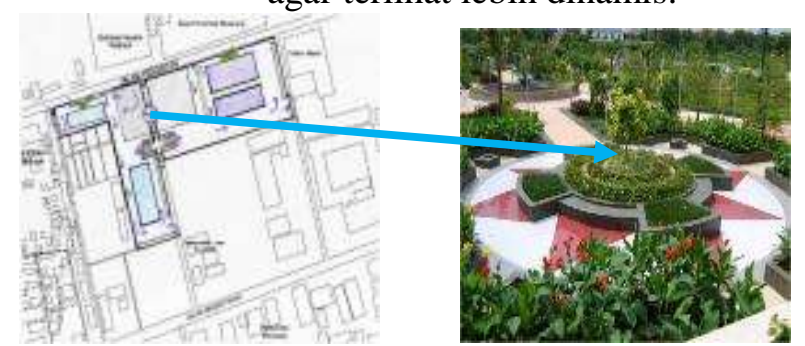

Gambar 8. Analisis Sculpture Penghubung Tapak

Hasil analisis, dengan memberikan sculpture di jalan lingkungan antara kedua tapak, pengunjung dapat mengetahui bangunan pasar ikan yang saling berhubungan (lihat Gambar. 8).

b. Menara pada mercusuar diadopsi untuk memasukkan cahaya dan penghawaan alami ke dalam bangunan, sehingga bangunan dapat memanfaatkan keadaan iklim di sekitar (lihat Gambar. 9).
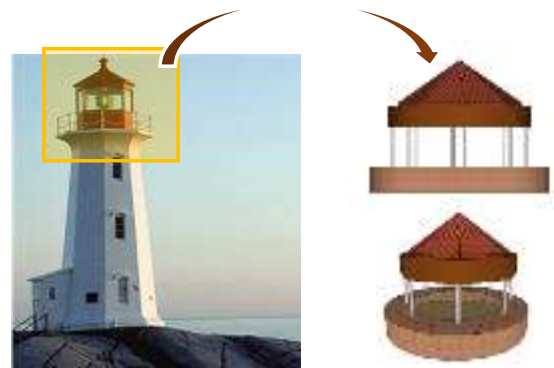

Gambar 7. Analisis Penghubung Bangunan

c. Interior Bangunan pada Exhibition Area

Exhibition area sebagai penghubung antara dua bangunan pada pasar ikan hias, sehingga terjadi kontak antar bangunan. Selain itu, exibition area diberikan split level (lihat Gambar. 10) agar jarak pandang pengunjung terhadap ikan yang dipamerkan lebih nyaman. Exhibition area memberikan dampak pada kondisi pasar ikan hias yang tadinya sepi akan menjadi ramai pengunjung.

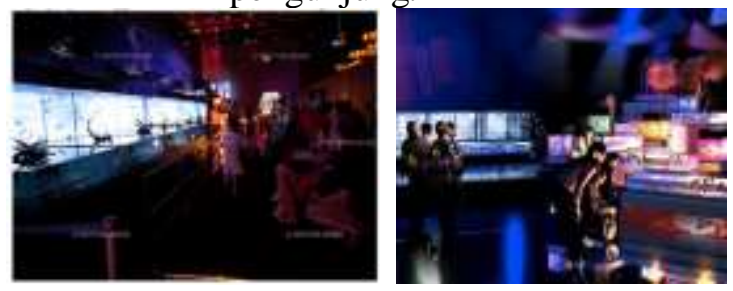

Gambar 10. Rencana Interior Exhibition Area (Sumber : www.nipponnews.net diakses pada 15 Mei 2015)

9. Analisis Material Bangunan Tujuan : Memperoleh material bangunan yang tepat dan nyaman bagi perilaku pengguna pasar, 
sehingga mampu mengatasi bentuk, iklim, dan kegiatan yang akan mewadahi dalam Revitalisasi Pasar Ikan Rejomulyo sebagai Destinasi Wisata.

Dasar Pertimbangan :

- Material bahan bangunan sesuai dengan kegiatan yang diwadahi dalam bangunan pasar ikan ini.

- Kecocokan bahan bangunan yang dipakai dengan konsep Arsitektur Perilaku.

Analisis :

a. Lantai

Ketinggian lantai minimal $20 \mathrm{~cm}$ dari permukaan tanah. Lantai harus tahan terhadap minyak ikan, lemak, minyak atau garam. Diberikan lantai dengan bahan lebih bertekstur.

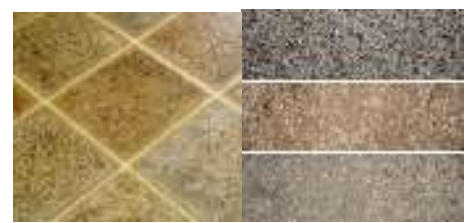

Gambar 11. Keramik Bertekstur

(Sumber : cat.tekstur.wordpress.com diakses pada 14 November 2014)

Pemilihan lantai (lihat Gambar. 11) akan berfungsi sebagai faktor kenyaman pengguna dalam melakukan kegiatan di pasar ikan yang kemungkinan terdapat banyak minyak atau air bertumpahan di lantai pasar.

b. Dinding

Permukaan dinding harus rata dan halus. Pertemuan sudut dinding dibuat melengkung (lihat Gambar. 12) sehingga mudah dibersihkan dan warna dinding terang agar tetap terjaga kebersihannya.

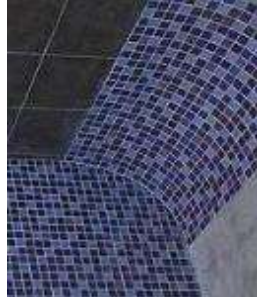

Gambar 12. Sudut Dinding Kios

(Sumber : www.ideaonline.co.id diakses pada 14 November 2014)

c. Penerangan

Ruangan pasar harus memiliki cahaya penerangan yang cukup. Dengan memberikan penutup atap yang dapat memberikan pencahayaan alami pada bangunan.

10. Analisis Utilitas

Tujuan :

Analisis sistem struktur bangunan bertujuan untuk memperoleh sistem utilitas yang tepat, efektif, dan efisien yang mampu mengatasi bentuk massa bangunan serta nyaman bagi perilaku penguna.

a. Sistem Pembuangan Limbah

Dasar Pertimbangan :

- Kesehatan lingkungan

- Kelancaran pembuangan

Analisis :

Air kotor yang berasal dari kios-kios, area servis, dan dapur, bangunan ini menggunakan sistem pengolahan limbah (Sewage Treatment Plant). Dengan sistem dari air kotor hingga dapat dimanfaatkan menjadi air bersih untuk kebutuhan jaringan pengaman kebakaran dan penyiraman halaman rumput.

Hasil analisisnya adalah proses pengolaham limbah yang dapat diolah dan dimanfaatkan kembali untuk kebutuhan kegiatan di dalam atau sekitar tapak.

b. Sistem Air Bersih 
Tujuan : Memperoleh distribusi air bersih yang baik untuk kegiatan pasar ikan Dasar Pertimbangan : Efisiensi dan efektivitas

Analisis : Terdapat dua macam sistem distribusi yang dapat digunakan,

\section{- Up Feed Distribution}

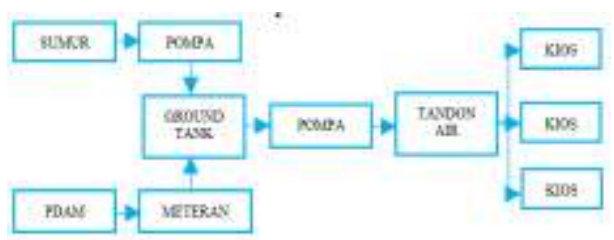

Gambar 13. Up Feed Distribution

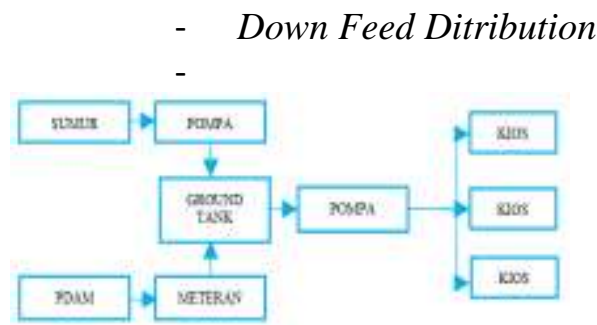

Gambar 14. Down Feed Distribution

Karena objek perencanaan merupakan pasar ikan, sehingga menuntut kenyamanan yang cukup tinggi untuk menjaga kualitas ikan. Dengan demikian, sistem yang digunakan merupakan gabungan dari ke dua sistem penyediaan air bersih (lihat Gambar 13 dan 14).

\section{KESIMPULAN (KONSEP DESAIN)}

Konsep perencanaan dan perancangan Pasar Ikan Rejomulyo ini mengacu untuk menjadikan pasar yang bersih, nyaman, dan rekreatif sehingga menjadikan pasar yang efektif dan efisien sebagai destinasi wisata kota (lihat Gambar. 15). Perwujudan pasar yang efektif dan efisien dengan dua tapak yang berbeda dengan pemberian underpass dan pedestrian (lihat Gambar. 18). Selain itu, pasar ikan sebagai destinasi wisata diwujudkan dengan pemberian rooftop area sebagai tempat bersantai (lihat Gambar. 17) dan exhibition area untuk pameran ikan (lihat Gambar. 18). Keseluruhan massa bangunan pasar ikan merupakan satu kesatuan fungsi yang dirancang sedemikian rupa sehingga memiliki kenyaman secara fisik maupun psikis bagi penggunanya (lihat Gambar. 17).

Berdasarkan hasil analisis serta hasil korelasi dari beberapa data di atas, maka diperoleh hasil berupa rancangan Revitalisasi Pasar Ikan Rejomulyo sebagai Destinasi Wisata Kota Semarang, sebagai berikut :
Nama
: Pasar Ikan Rejomulyo
Lokasi
: Jl. Pengapon, Semarang
Luas Lahan
$: \pm 25.000 \mathrm{~m}^{2}$
Kegiatan
: Jual-beli dan rekreasi

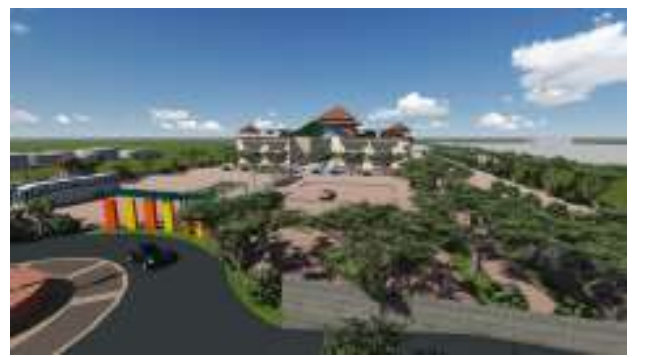

Gambar 15. Perspektif Pasar Ikan Rejomulyo

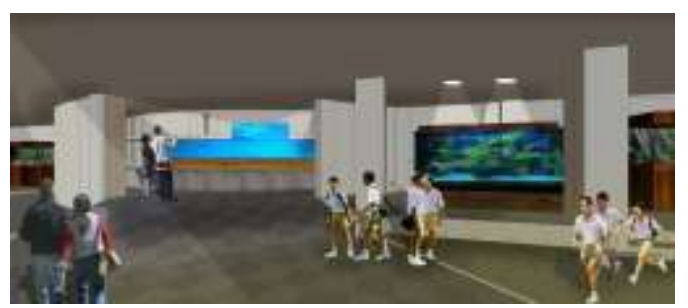

Gambar 16. Interior Exhibition Area

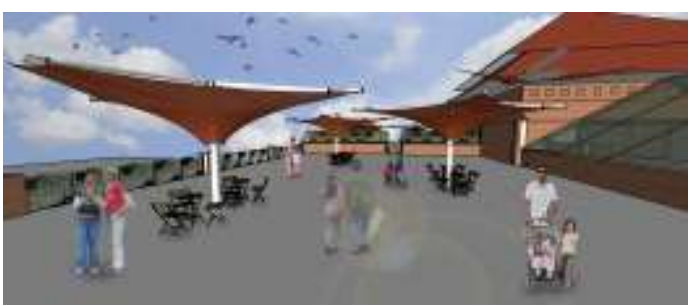

Gambar 17. Rooftop Area Pasar Ikan Hias

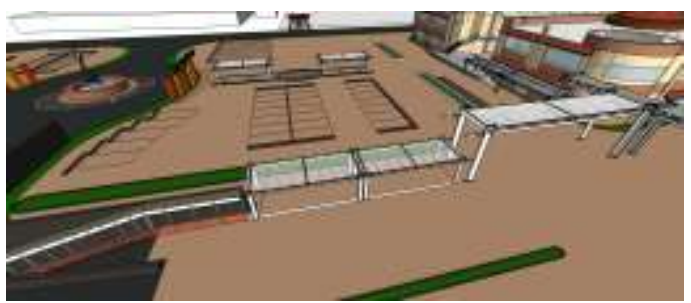

Gambar 18. Pedestrian Pasar Ikan Rejomulyo 


\section{REFERENSI}

www.bappeda.semarangkota.go.id, mengenai Data Pariwisata Kota Semarang diakses pada 13 November 2014

www.bps.semarang.go.id, mengenai Tinjauan Umum Kota Semarang diakses pada 13 November 2014

www.cat.tekstur.wordpress.com, mengenai jenis penutup lantai diakses pada 14 November 2014

www.ideaonline.co.id, mengenai dinding melengkung pada pasar ikan diakses pada 14 November 2014

www.nipponnews.net, mengenai interior pameran ikan diakses pada 15 Mei 2015 